\title{
Penerapan Model Promosi Berbasis Web Captive Portal Hotspot dengan Manajemen Terpusat
}

\author{
Hariadi Yutanto \\ STIE Perbanas Surabaya
}

Naskah Diterima : 9 Januari 2019; Diterima Publikasi : 9 April 2018

DOI : 10.21456/vol8iss1pp49-56

\begin{abstract}
The current technological developments so rapidly with speed and supported the ease of internet services. The Internet has also become one of the main needs of everyday human life activities. Internet advertising media innovation is one of the key media promotion in following the development of technology. Web-based portal advertising hotspot media for internet connection services is the most widely used today, as almost all agencies, offices, hotels, restaurants, schools / internet service providers (ISPs) use this technology. Hotspot network management techniques on mikrotik router captive portal can be used as a webbased promotion media and can be used as a centralized and dynamic media settings. Advertising media can be determined by location by combining 2 methods ie eoip and bridge for lan network while eoip, vpn and bridge on wan network. The results of this research has been working optimally and implemented in the network lan STIE Perbanas Surabaya while for wan network has been tested using the internet network in several locations civitas house.
\end{abstract}

Keywords : Promotion Media; Hotspot; Captive portal; Mikrotik; EOIP; VPN; Bridge

\begin{abstract}
Abstrak
Perkembangan teknologi saat ini begitu pesat dengan kecepatan dan didukung kemudahan layanan internet. Internet juga telah menjadi salah satu kebutuhan utama kegiatan kehidupan manusia sehari-hari. Inovasi media periklanan internet merupakan salah kunci satu media promosi dalam mengikuti perkembangan teknologi. Media iklan hotspot portal berbasis web untuk layanan koneksi internet adalah yang paling banyak digunakan saat ini, karena hampir semua instansi, perkantoran, hotel, restoran, sekolah / kampus dan penyedia layanan internet (ISP) menggunakan teknologi ini. Teknik pengelolaan jaringan hotspot pada router mikrotik captive portal dapat dimanfaatkan sebagai media promosi berbasis web dan dapat digunakan sebagai media pengaturan yang terpusat dan dinamis. Media periklanan dapat ditentukan berdasarkan lokasi dengan cara mengkombinasikan 2 metode yaitu eoip dan bridge untuk jaringan lan sedangkan eoip, vpn dan bridge pada jaringan wan. Hasil penelitian ini telah bekerja secara optimal dan diimplementasi pada jaringan lan STIE Perbanas Surabaya sedangkan untuk jaringan wan telah dilakukan uji coba menggunakan jaringan internet di beberapa lokasi rumah sivitas.
\end{abstract}

Kata kunci: Media Promosi; Hotspot; Captive portal; Mikrotik; EOIP; VPN; Bridge

\section{Pendahuluan}

Perkembangan teknologi informasi terutama dibidang internet dan jaringan luas berkembang pesat. Teknologi informasi dan komunikasi sangat bermanfaat, berdayaguna tinggi dan mendukung semua proses bisnis. Layanan internet merupakan fasilitas utama saat ini bagi perusahaan, hotel, restoran/cafe, sekolah, semua saling berlomba-lomba untuk memberikan layanan terbaik.

Teknologi jaringan nirkabel atau yang lebih dikenal dengan hotspot merupakan teknologi jaringan yang umum ditemui untuk saat ini. Captive Portal adalah suatu teknik autentikasi bagi pengguna dan pengamananan data sebelum terkoneksi ke jaringan

*) Penulis korespondensi: antok@perbanas.ac.ic internal dan eksternal. Captive Portal merupakan sebuah perangkat router atau gateway yang memproteksi jaringan, sampai pengguna melakukan login terlebih dahulu kedalam system Captive Portal pada umumnya digunakan pada infrastruktur jaringan wireless seperti hotspot area, akan tetapi tidak menutup kemungkinan diterapkan pada infrastruktur jaringan kabel. (Hermawan dan Sudarsono, 2010).

Jika jaringan hotspot yang dikelola menggunakan Router Mikrotik dapat dikembangkan sebagai media promosi melalui web dengan memanfaatkan halaman portal login dan dapat dilukan secara terpusat akan memudahkan bagi admin jaringan dan meningkatkan promosi berbasis portal hotspot. Peneliti mencoba mengembangkan penelitian sebelumnya yaitu 
integrasi captive portal hotspot mikrotik dengan unifi controller (Yutanto, 2015). Pada penelitian ini penelitian menggunakan kombinasi 2 metode yaitu virtual private network (vpn) dan tunnel Ethernet Over Internet Protocol (EoIP) untuk menggabungkan seluruh jaringan hotspot secara terpusat baik pada jaringan intranet maupun internet. Tujuan dari penelitian ini adalah dapat memanfaatkan media captive portal sebagai media promosi yang memanfaatkan jaringan lan dan wan. Hasil Penelitian ini diharapkan dapat memberikan manfaat bagi instansi/kampus/sekolah/restoran/hotel yang akan memanfaatkan router mikrotik dengan biaya relatif murah sebagai media promosi.

\section{Kerangka Teori}

\subsection{Jaringan Komputer}

Interkoneksi dua atau lebih komputer yang terhubung melalui media transmisi kabel atau nirkabel dan dirancang dengan protokol komunikasi agar dapat bekerja sama dalam mencapai tujuan dan manfaat utama, kedua komputer dikatakan terhubung apabila dapat saling bertukar data dan informasi(Taufan, 2001). Jaringan komputer dapat diartikan pula sebagai kumpulan sejumlah terminal komunikasi yang berada di berbagai lokasi yang terdiri dari lebih dari satu komputer yang saling berhubungan. Tujuan jaringan komputer dibangun untuk membawa informasi secara tepat dan tanpa adanya kesalahan dari sisi pengirim (transmitter) menuju ke sisi penerima (reciever) melalui media komunikasi. Protokol adalah sebuah aturan yang mendefinisikan beberapa fungsi yang ada dalam sebuah jaringan komputer, misalnya mengirim pesan, data, informasi dan fungsi lain yang harus dipenuhi oleh si pengirim (transmitter) dan si penerima (reciever) agar komunikasi dapat berlangsung dengan benar.

Selain itu protokol juga berfungsi untuk memungkinkan dua atau lebih komputer dapat berkomunikasi dengan bahasa yang sama (Sukmaaji dan Rianto, 2008). Penggunaan jaringan komputer menjadi sangat popular saat ini dikarenakan pelayanan informasi menjadi semakin cepat dan tidak hanya memenuhi kebutuhan individu melainkan kebutuhan massal. Jaringan komputer saat ini bahkan telah mencapai koneksi global (dunia) yakni dengan adanya internet. Tinggi penggunaan internet dan maranya penggunaan hotspot pada area umum dan di setiap instansi, hotel, perguruan tinggi belomba-lomba memberikan fasilitas layanan internet, hal itu yang dapat dimanfaatkan sebagai media promosi setiap pemberi layanan.

\subsection{Mikrotik Router}

Mikrotik router merupakan sebuah perangkat jaringan komputer berbasis Linux dan diperuntukkan bagi network router. Mikrotik router memiliki beberapa fasilitas seperti hotspot bandwith management, stateful firewall, remote Winbox GUI admin, dan routing. Administrasi Mikrotik router dapat dilakukan melalui aplikasi WinBox. Pada saat ini, WinBox telah di tampilkan secara graphical dan web base sehingga user dengan mudah dapat mengakses dan mengkonfigurasi router sesuai kebutuhan dengan mudah efektif dan efisien. Memperkecil kesalahan pada waktu setup konfigurasi, mudah dipahami dan customable sesuai yang diinginkan. Winbox merupakan software atau utility yang di gunakan untuk meremote router mikrotik ke dalam mode GUI (Graphical User Interface) yang diakses melalui operating system windows.

\subsection{Hotspot}

Hotspot (Wi-Fi) adalah salah satu bentuk pemanfaatan teknologi WirelessLAN, pertama kali digagas tahun 1993 oleh Brett Steward (Haryadi, 2016). Captive Portal merupakan juga dikenal dalam istilah Hotspot. Captive Portal akan menerima semua trafik dari client dan akan memeriksa apakah client tersebut telah melakukan otorisasi atau belum untuk menggunakan sumber daya jaringan. Jika belum maka client tersebut akan diperiksa untuk melakukan athentifikasi terlebih dahulu (Supriyono dan Riadi, 2013). Dalam pengelolaan infrastruktur jaringan hotspot langkah pertama yaitu menentukan lokasi/letak server hotspot dan juga memperhatikan letak wifi lainnya yang akan dihubungkan, jangkauan kabel UTP Rj-45 maksimum 100 meter dan lebih dari 100 meter perlu dipasang Switch hub atau router (Rahmat Rafiudin 2003), switch hub ini berkemampuan untuk memperkuat signal dan hisa dihuhungkan ke beberapa wifi lain.

\subsection{Captive Portal}

Dalam penelitiannya Haryadi (2016) yaitu teknik media otentikasi Captive Portal dan keamanan data yang melintas dari jaringan eksternal ke jaringan internal. Captive Portal adalah perangkat router atau gateway untuk melindungi atau tidak membiarkan lalu lintas apapun, sampai pengguna melakukan registrasi ke sistem sebelumnya. Captive Portal biasanya digunakan di infrastruktur nirkabel seperti area hotspot, namun tidak berlaku untuk jaringan kabel.

Pada Gambar 1 captive portal bekerja dengan mengalihkan semua request untuk akses HTTP dari user ke halaman khusus yang biasanya berupa halaman otentikasi pengguna yang berisi pertanyaan seperti username dan password atau kesepakatan halaman antara pengguna dan provider. dari jaringan nirkabel yang berfungsi melakukan otentikasi, sebelum pengguna mengakses internet. Pengalihan permintaan http dibuat dengan menginterupsi semua paket dan mengabaikan alamat apapun. 


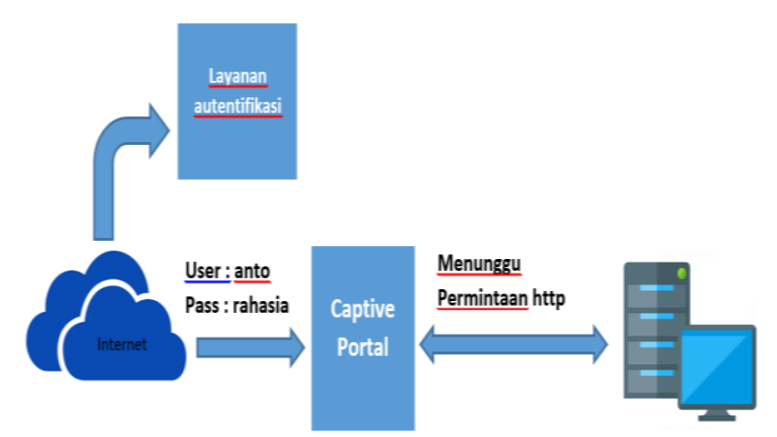

Gambar 1. Autentifikasi Captive Portal

\section{5. $V P N$}

Virtual Private Network (VPN) atau jalur komunikasi khusus yang efisien menggunakan internet. VPN digunakan untuk menelaah mereka yang membutuhkan Ulasan ruang mereka sendiri di Internet (Madjid, 2006). Sebagai contoh komunitas yang membutuhkan keamanan jaringan di Internet dapat melakukan pertukaran informasi di lingkungannya sendiri. VPN berjalan pada topologi yang membuat terowongan khusus. Pada Gambar 2 dapat dilihat infrastuktur jaringan VPN. Fungsi VPN adalah untuk memberikan koneksi yang aman antara pengguna jasa yang terhubung melalui internet ke jaringan internal. Umumnya VPN diimplementasikan oleh instansi lain /perusahaan besar. Biasanya Ulasan Perusahaan-perusahaan ini memiliki cabang yang cukup jauh dari markas. Jadi, kita butuh solusi yang tepat untuk Mengatasi keterbatasan LAN. VPN bisa jadi pilihan yang cukup tepat. Tentu VPN bisa diimplementasikan oleh pengguna rumahan atau oleh siapa saja yang membutuhkannya. Secara garis besar bagaimana VPN adalah sebagai berikut (Gambar 2):

a. Sebuah. VPN mendukung banyak protokol jaringan seperti PPTP, L2TP, IPsec dan SOCK, dimana dukungan protokol-protokol VPN bekerja untuk proses otentikasi.

b. Client VPN dilakukan oleh pengguna terpercaya yang telah diberi akses oleh administrator jaringan.

c. Jaringan VPN juga dienkripsi untuk meningkatkan keamanan.

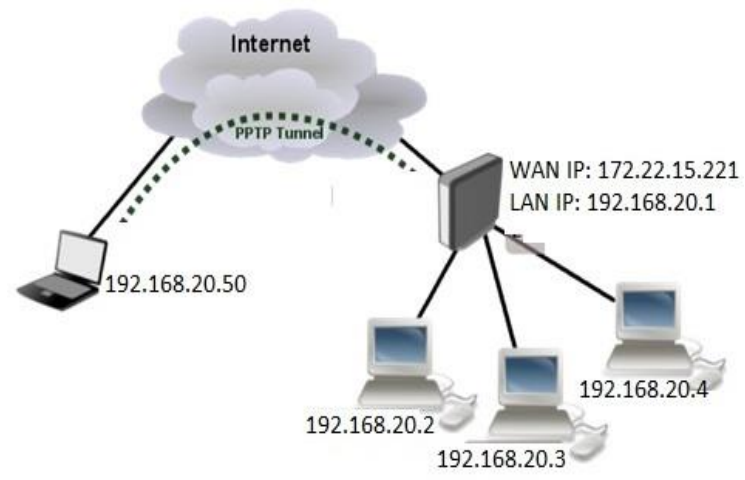

Gambar 2. Jaringan VPN

\subsection{EOIP}

Ethernet over IP (EoIP) adalah fitur yang dimiliki oleh teknik Mikrotik Router untuk menerapkan jembatan pada jaringan yang berjauhan, misalnya dipisahkan oleh Internet. Dalam implementasi fitur EOIP harus menggunakan router proxy, EoIP akan membuat terowongan yang melintasi internet untuk menghubungkan dua atau lebih router. (Mikrotik.co.id). Infrastktur jaringan EOIP dapat dilihat pada Gambar 3 jalur tunnel EOIP, berbeda dengan VPN yang bekerja menggunakan akses internet, EOIP berada di layer 2 dalam OSI layer atau dapat bekerja pada jaringan lan

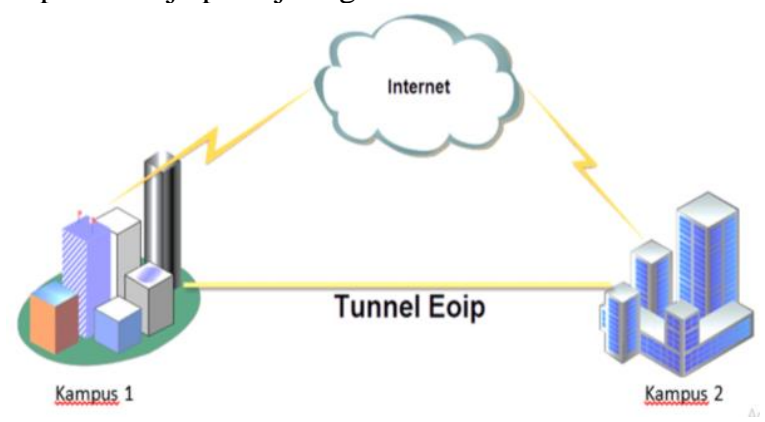

Gambar 3. Jaringan EoIP

\subsection{Penelitian Terdahulu}

Penelitian Chandra (2015) mencoba untuk mengembangkan teknologi media iklan web berbasis lokasi dengan memanfaatkan segmentasi jaringan pada lokal area network. Penelitian ini menggunakan teknik manipulasi jaringan dan penentuan posisi dari perangkat jaringan sebagai media iklan yang dinamis, dapat berubah-ubah sesuai dengan lokasi. Teknik manipulasi jaringan yang digunakan adalah DHCP Server, DHCP Relay, dan teori dasar mengenai subnetting. Di mana setiap lokasi memiliki satu segmen atau subnet, sehingga jika ada akses dari subnet tersebut, pengguna akan diarahkan dengan menggunakan network address translation, menuju halaman iklan sesuai dengan pembagian segmen yang sudah ditentukan sebelumnya. Dari penelitian tersebut dapat disimpulkan bahwa Segmentasi jaringan dapat diaplikasikan untuk pembagian wilayah, namun kurang optimal untuk dijadikan acuan penentu lokasi. Sedangkan untuk penentuan lokasi dalam kasus ini disempurnakan dengan menggunakan filteringmacaddress pada OSI layer 2.

Aryanto dan Cahyo (2014) dalam penelitiannya bagaimana membangun website portal sebagai sarana barang dan jasa di Yogjakarta, tahap awal yang dilakukan dengan melakukan perancangan program, dan melakukan pengujian apakah dengan penggunaaan website dapat menguntungkan bagi pengguna dalam melakukan usaha penyewaan barang dan jasa. Penggunaan website portal semakin memudahkan pengguna dan dapat dipercaya karena memoderasi iklan langsung dan dilakukan oleh admin dan data lokasi yang ditampilkan dalam bentuk peta. 
Setiawan (2013) dalam penelitiannya mengembangkan rancang bangun captive portal untuk jaringan wireless hotspot berbasis open source pada perusahaan Event Organizers di Palembang. Captive portal menjadi mekanisme populer bagi infrastruktur komunitas WiFi dan operator hotspot yang memberikan authentikasi bagi pengguna. Pada penelitian ini dibangun sebuah teknologi Captive Portal untuk jaringan hotspot dengan menggunakan perangkat lunak open source Coova Chilli, FreeRadius dan sistem operasi Debian 6 (squeze) Server. Dari penelitian tersebut hotspot server diperlukan untuk meningkatkan keamanan jaringan wireless hotpot dengan menggunakan autentifikasi user sehingga hak akses user ke jaringan dapat diatur secara terpusat. Hotspot server ini menggunakan perangkat lunak easyhotspot, freeradius, dan coova chili yang di dukung oleh Database MYSQL. Coova chili memberikan IP Tunnel dan memberikan halaman captive portal. Penerapan sistem autentifikasi user akan memberikan tingkat keamanan jaringan wireless yang lebih baik. User yang dapat menggunakan layanan jaringan harus terdaftar dalam system sehingga tidak semua orang dapat menggunakan layanan jaringan. Dengan adanya autentifikasi user, admin jaringan dapat melakukan monitoring akses pengguna layanan jaringan.

Supriyono dan Riadi (2013) dalam penelitiannya mengembangkan system hotspot menggunakan captive portal. Pengumpulan data yang digunakan menggunakan metode observasi, wawancara dan metode studi literatur. Sistem yang dibangun adalah captive portal menggunakan aplikasi freeradius dan chillispot. Penyusunan meliputi dengan prosedur antara indentifikasi masalah, analisis kebutuhan, perancangan jaringan, perancangan sistem, serta implementasi jaringan hotspot menggunakan metode captive portal, sedangkan pengujian sistem dilakukan dengan black box dan alpha test. Hasil penelitian dapat bekerja dengan optimal pada rancang bangun sistem hotspot menggunakan captive portal dan sistem yang mampu meningkatkan keamanan akses jaringan. Sehingga mempermudah admin jaringan dalam monitoring aktivitas pengguna yang sedang aktif pada jaringan hotspot. Berdasarkan hasil uji coba tersebut dapat disimpulkan bahwa captive portal ini dapat diterapkan pada sistem hotspot.

Goeritno et al. (2017) dalam penelitiannya mengembangkan system hotspot yang terintegasi dengan system informasi akademik dan keuangan (SIAK) di univeristas ibn Khaldun (UIKA) Bogor. Keberadaan web portal dengan metode single sign on (SSO) ini, berarti setiap user hanya perlu satu nama pengguna (user name) dan kata sandi (password). Untuk perolehan layanan atau fasilitas di web portal, setiap user hanya perlu login satu kali saja dalam penggunaan semua fasilitas atau layanan aplikasi yang terdapat di dalam web portal tersebut. Tujuan penelitian ini, yaitu (i) memperoleh mekanisme dalam penggunaan aplikasi dengan satu account dan sekali login bagi end user dan (ii) memperoleh pengamanan hak akses layanan hotspot dan SIAK. Hasil yang diperoleh berupa implikasi terhadap bentuk kemudahan dalam pelaksanaan login, sehingga diperlukan pengorganisasian data user. Lebih lanjut diperoleh keterjaminan data user berkaitan dengan penggunaan tempat penyimpanan data user secara terpusat, agar semua aplikasi dapat diintegrasikan ke dalam sebuah web portal.

\section{Metode}

\subsection{Waktu dan Lokasi Penelitian}

Penelitian Penelitian ini dimulai pada bulan Januari 2017 dengan objek penelitian pada jaringan di STIE Perbanas Surabaya.

\subsection{Metode Penelitian}

Kerangka kerja menggunakan metode pengembangan sistem air terjun merupakan pendekatan pengembangan aplikasi yang sistematis dan berurutan dimulai pada tingkat sistem dan kemajuan pada semua kebutuhan, analisis, perancangan, implementasi, pengujian, dan pemeliharaan. Pengembangan sistem jaringan ini menggunakan linear sequential. Metode ini adalah metode yang paling banyak digunakan oleh pengembang perangkat lunak. Metode ini biasa disebut metode waterfall (Gambar 4), dimana pelaksanaan suatu sistem dilakukan secara berurutan atau linier. Dimulai dari

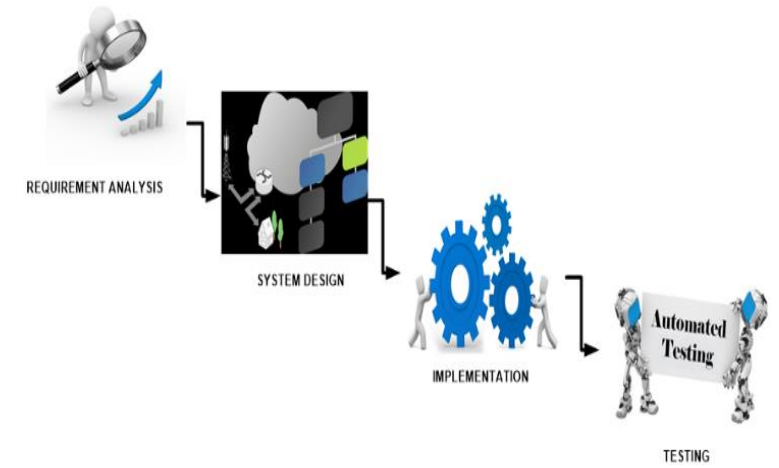

Gambar 4. Metodologi Waterfall

\subsection{Metode Pengumpulan Data}

Metode yang digunakan penulis dalam melakukan penerapan model promosi berbasis web captive portal hotspot dengan manajemen terpusat yaitu :
a. Obeservasi
Observasi dilakukan dengan cara mengamati dan melakukan analisa terhadap desain infrastruktur jaringan di STIE Perbanas Surabaya.
b. Diskusi dan Wawancara
Melakukan diskusi dan wawancara langsung dengan bagian admin jaringan / network administrator mengenai hal-hal yang berhubungan dengan objek yang akan ditinjau. 


\section{c. Studi Pustaka}

Untuk mendapatkan pengetahuan dan data yang bersifat teoritis untuk mendukung penelitian yaitu dengan cara membaca literature yang relevan dengan pengamatan yang penulis lakukan. Penulis mencari referensi melalui buku-buku, jurnal-jurnal yang berkaitan dengan permasalahaan.

\subsection{Tahapan Desain Sistem}

Pada Gambar 5 merupakan model desain Infrastuktur media promosi hotspot. Setiap user yang terkoneksi pada lokasi wifi, user akan akan mengikuti tampilan captive portal setiap lokasi baik yang menggunakan jaringan LAN dan MAN maupun WAN. Semua aktivitas user dan tampilan web Captive Portal akan terpusat dalam pengelolaan 1 Server hotspot.

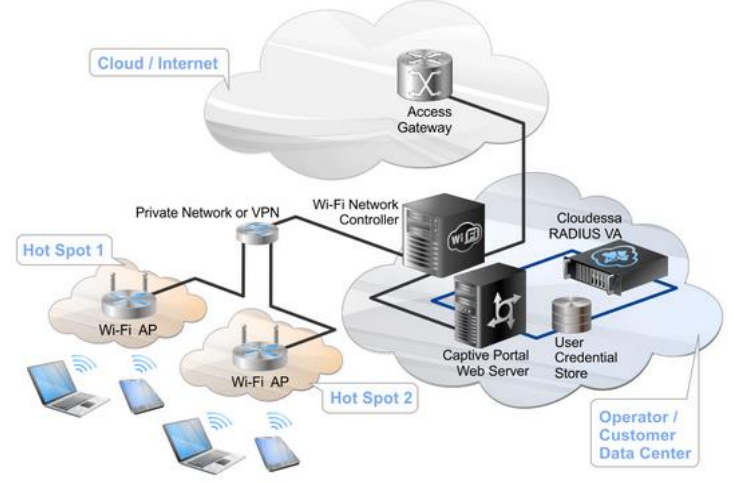

Gambar 5. Desain infrastruktur

\section{Hasil dan Pembahasan}

Saat ini Infrastruktur Jaringan Wifi hotspot STIE Perbanas memiliki total 34 titik yang terbagi di 2 lokasi kampus, 19 titik di kampus 1 dan 17 titik hotspot di kampus 2. Seluruh perangkat access point menggunakan Unifi dan terkontrol menjadi 1 pada server unifi controller. Untuk router core menggunakan Mikrotik CCR koneksi antar router kampus 1 dan kampus 2 menggunakan jaringan localloop wireless, pada Gambar 6 dan Gambar 7 merupakan infrastruktur jaringan wireless baik dikampus 1 maupun kampus 2

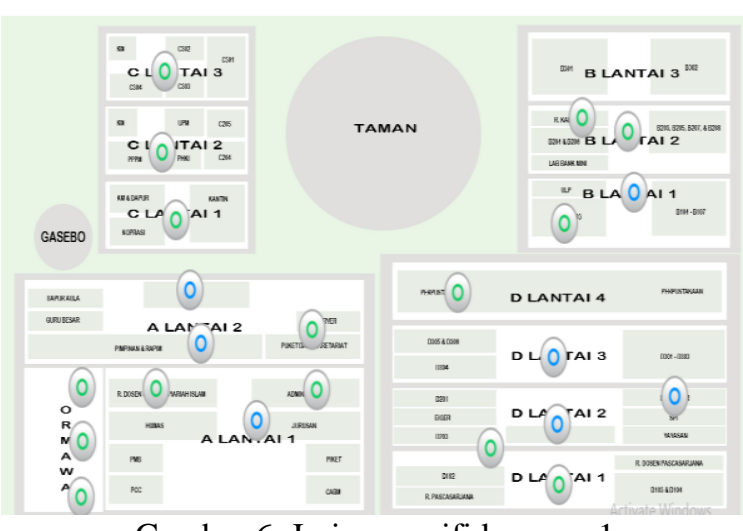

Gambar 6. Jaringan wifi kampus 1
Tahapan implementasi media iklan web portal di STIE Perbanas Surabaya dibagi menjadi 3 tahap besar yaitu untuk media promosi jaringan lan menggunakan kombinasi tunnel eoip dengan bridge sedangkan untuk jaringan wan menggunakan kombinasi tunnel eoip, vpn, dan bridge. Tahapan selanjutnya setelah infrastruktur telah terkoneksi dengan baik adalah melakukan desain media promosi captive portal berdasarkan lokasi.

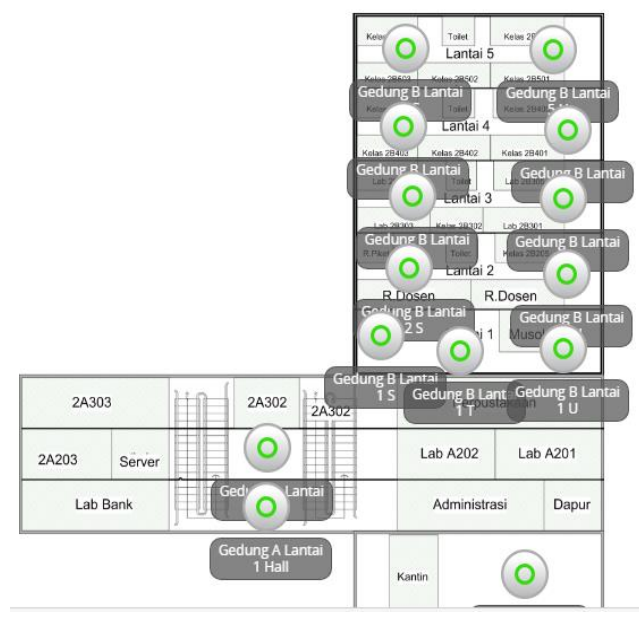

Gambar 7. Jaringan wifi kampus 2

\subsection{Konfigurasi Mikrotik Hotspot Untuk Tunnel EOIP}

Pada Gambar 8 merupakan tahapan konfigurasi mikrotik hotspot untuk penggunaan tunnel eoip baik itu untuk jaringan LAN maupun untuk jaringan WAN. Pada Gambar 8 (a) merupakan router mikrotik untuk gedung D yang terkoneksi dengan router server hotspot (b)

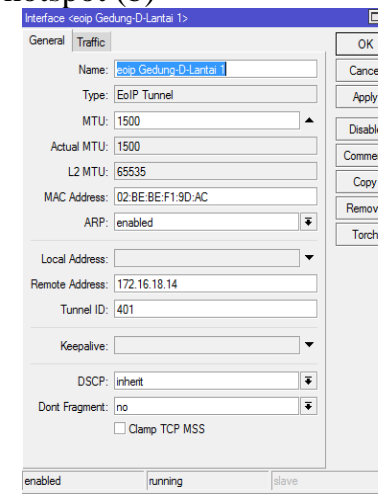

(a) EOIP Gedung D

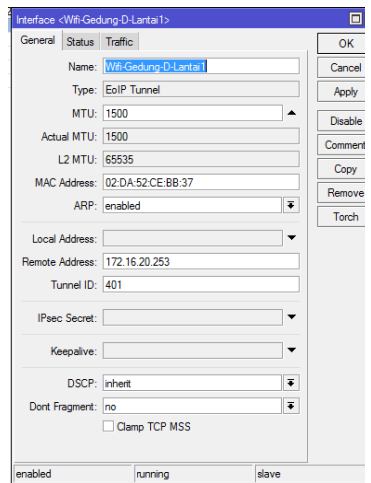

(b) Server Hotspot
Gambar 8. Tahapan konfigurasi mikrotik hotspot

Hasil konfigurasi infrastruktur dari jaringan lan untuk media promosi dapat dilihat pada Gambar 9, semua router antar gedung baik di kampus 1 dan kampus 2 terkoneksi ke router hotspot pusat. Desain untuk media promosi web captive portal akan terpusat pada router hotspot, sedangkan pada router gedung hanya digunakan sebagai distribusi tunnel untuk setiap perangkat wifi / access point. 


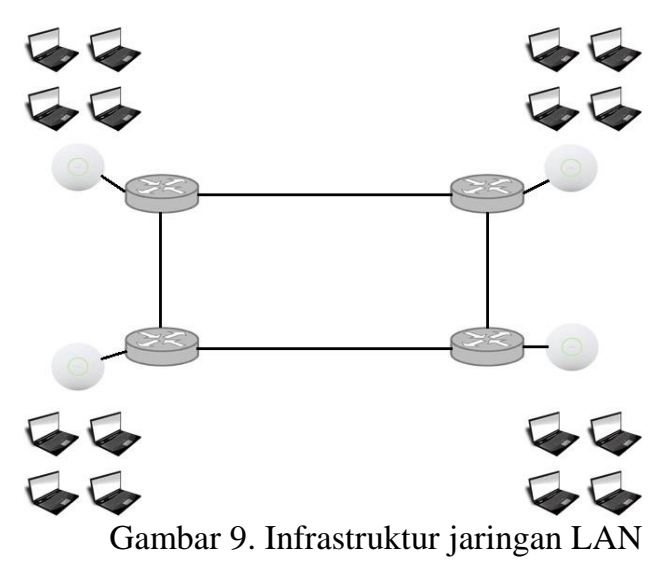

\subsection{Konfigurasi Jaringan WAN dengan VPN}

Tahap berikutnya adalah melakukan konfigurasi untuk jaringan koneksi menggunakan jaringan internet/wan, sama halnya dengan jaringan lan yang menggunakan tunnel eoip sebagai pembuatan hotspot, sedangkan untuk jaringan wan membutuhkan satu konfigurasi tambahan lagi yaitu menggunakan jaringan vpn terlebih dahulu ke server hotspot selain untuk keamanan jalur tersebut memastikan koneksi antara server hotspot dengan router client. Setelah terkoneksi dengan server hotspot pusat dilanjutkan dengan membentuk koneksi eoip tunnel. Proses vpn dan eoip akan dikombinasikan dengan konfigurasi bridge pada router mikrotik client. Pada Gambar 9 merupakan konfigurasi jalur koneksi vpn dari router pusat ke router client. Untuk vpn menggunakan pptp yang merupakan fasilitas yang juga dapat digunakan pada mikrotik router.

Hasil infrastruktur dapat dilihat pada Gambar 10 dari koneksi web captive portal menggunakan jaringan WAN
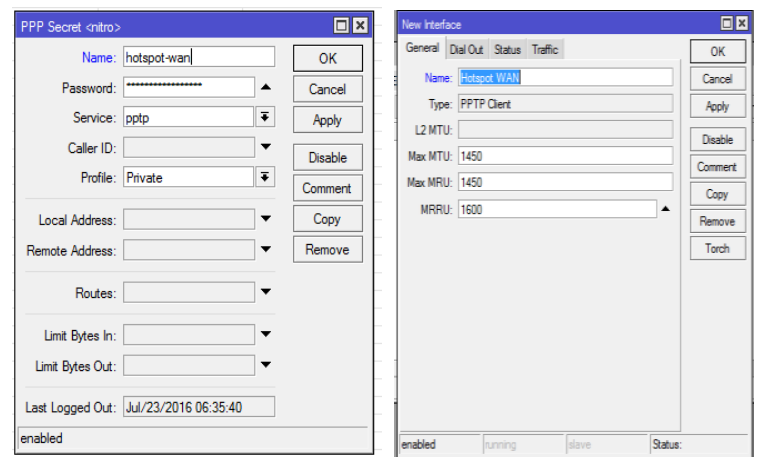

Gambar 10. VPN

Hasil konfigurasi infrastruktur dari jaringan wan untuk media promosi dapat dilihat pada Gambar 11, semua router akan terkoneksi ke router hotspot pusat menggunakan koneksi vpn, eoip dan bridge. Desain untuk media promosi web captive portal akan terpusat pada router hotspot, sedangkan pada router di sisi rumah sivitas hanya digunakan sebagai distribusi tunnel untuk setiap perangkat wifi / access point.

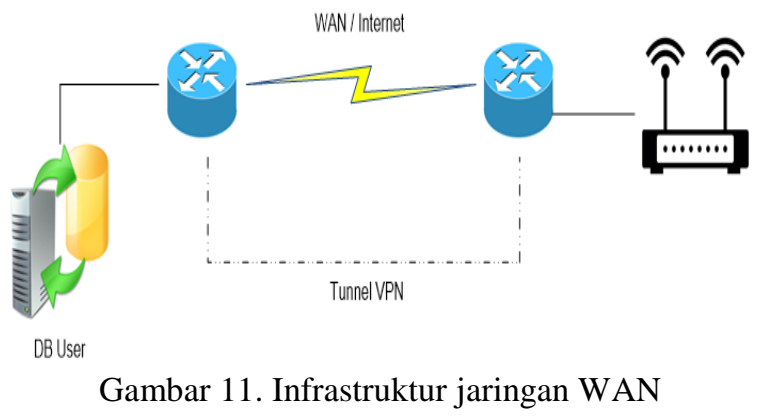

\subsection{Konfigurasi Captive Portal}

Setelah infrastruktur jaringan LAN dan WAN telah terbangun dan terhubung,, langkah berikutnya adalah untuk memanipulasi tampilan captive portal. Manipulasi ini berdasarkan router wifi sesuai dengan lokasi, konfigurasi captive portal digunakan sebagai hotspot server pusat antara lain konfigurasi fitur IP Address, Route, Firewall,DHCP, hotspot.

Manajemen hotspot server pada konfigurasi pengaturan IP Address alokasi IP dapat disesuaikan dengan alokasi IP lokasi. Kemudian konfigurasi hotspot seperti nama domain, dns, melalui menu sampai setting wizard hotspot captive Portal model desain. Setelah itu mendesain tampilan template captive portal dapat disesuaikan dengan kebutuhan yang kemudian diupload pada server hotspot.

Pada hasil penelitian ini ada tiga captive portal, antara lain lokasi kampus 1, 2, dan lokasi di luar kampus/wan. Pada Gambar 12 dan 13 merupakan infrastruktur berseta captive portal untuk media promosi, tampilan kampus 1 dan kampus 2 didesain dibuat hampir sama hanya ada identitas lokasi wifi.

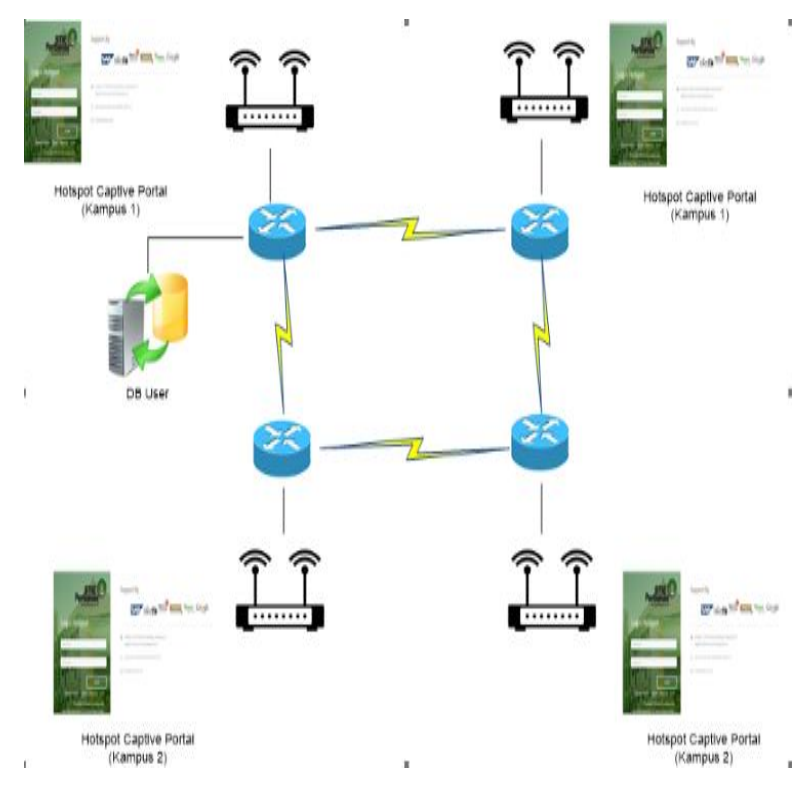

Gambar 12. Infrastruktur Captive Portal 


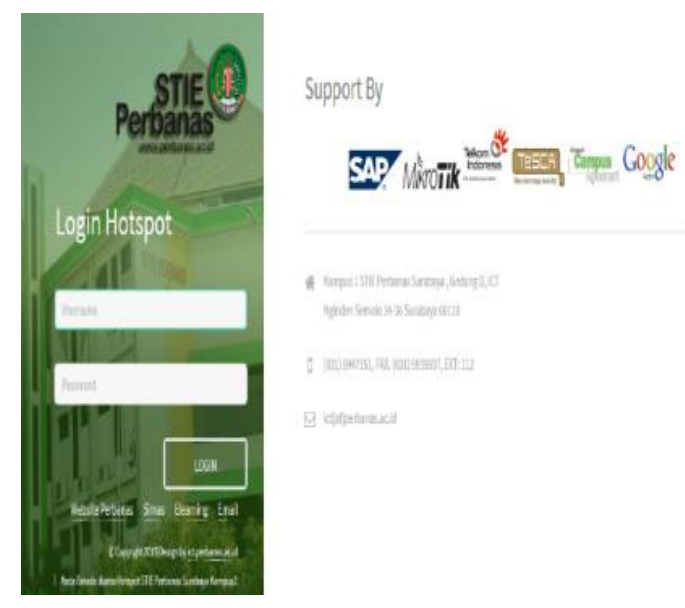

Gambar 13. Captive Portal jaringan LAN

Pada Gambar 14 dan 15 dapat dilihat infrastruktur jaringan beserta tampilan media promosi melalui jaringan wan yang dibuat berbeda secara layout dan tampilan yaitu dengan nama PHATH ( Perbanas Hotspot at The Home ).

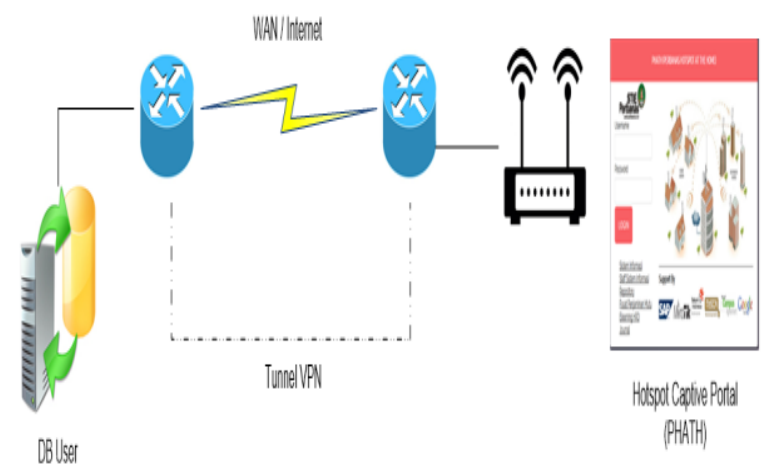

Gambar 14. Infrastruktur Captive Portal jaringan WAN

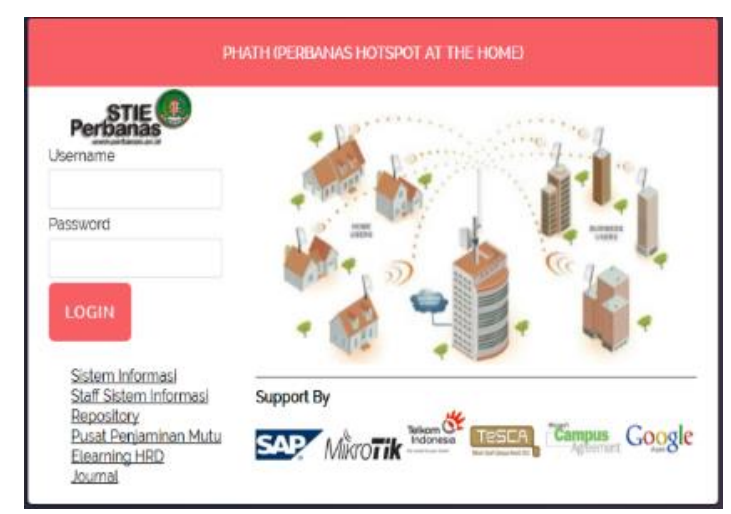

Gambar 15. Captive Portal jaringan WAN
Pada Gambar 16 yaitu hasil dari percobaan untuk monitoring terhadap semua pengguna hotspot di STIE Perbanas Surabaya, aktivitas user dapat dipantau secara terpusat pada router server hotspot pada masing-masing wifi accespoint. Pada hasil percobaan dan implementasi captive portal berjalan lancar dari sisi jaringan lan maupun menggunakan jaringan wan, untuk jaringan wan akan bergantung kepada kecepatan akses internet pada setiap lokasi akan tetapi web captive portal tetap dapat diakses dengan mudah.

\begin{tabular}{|c|c|c|}
\hline GGedung A Admin & supydit & 10.10.27.169 \\
\hline (9Gedung A Admin & magang & 10.1027 .60 \\
\hline Geedung A Admin & |atanza & 10.10 .27 .67 \\
\hline GGedung A Admin & aก่ร & 10.10.27.52 \\
\hline G Gedung A Lantai 1 R.Junssan & isma & 10.10.13.85 \\
\hline G Gedung A Lantai 1 R.Junsaan & nund & 10.10.13.204 \\
\hline Gedung A Lantai 1 R.Junsan & magang.keriasama & 10.10.13.77 \\
\hline GGedung A Lantai 1 R.Junsan & magangahumas & 10.10.13.45 \\
\hline G Gedung A Lantai 1 R.uunsan & 2012310047 & 10.10.13.198 \\
\hline GGedung A Lantai 1 R.Junssan & 2012211015 & 10.10 .13 .203 \\
\hline Gedung AOmawa Selatan & 2015310395 & 10.10 .24 .136 \\
\hline G Gedung A Omawa Selatan & 2015210358 & 10.10 .24 .134 \\
\hline Gedung AOmawa Selatan & 2014310507 & 10.10.24.137 \\
\hline GGedung AOmawa Selatan & 2014310272 & 10.10.24.144 \\
\hline GGedung A Omawa Selatan & 2014210854 & 10.10.24.177 \\
\hline GGedung AOmawa Seldan & 2014210513 & 10.10 .24 .164 \\
\hline G Geodung A Omawa Seldan & 2014210462 & 10.10 .24 .106 \\
\hline
\end{tabular}

Gambar 16. Aktvitas User Per lokasi

Secara keseluruhan hasil dari Penerapan captive portal sebagai media promosi dapat memberikan kemudahan bagi pengguna hotspot baik di dalam LAN atau di WAN, untuk mengakses captive portal yang ada di rumah sivitas menggunakan jaringan WAN selain memberikan keamanan, user sivitas juga dapat mengakses data lokal server dan mengakses jurnaljurnal berlangganan seperti Ebsco tanpa menggunakan authentifikasi dikarenakan didaftarkan menggunakan IP Public STIE Perbanas Surabaya. Kelemahan dari lokasi sistem captive portal berbasis jaringan WAN adalah kebutuhan untuk menggunakan router mikrotik, sehingga pengguna yang ingin menggunakan hotspot perbanas, setiap rumah sivitas harus memiliki router mikrotik dan koneksi internet. Model Promosi dari hasil pembahasan konfigurasi dapat dilakukan dengan cara mengganti layout tampilan pada server berdasarkan masing-masing lokasi, layout tersebut dapat didesain sesuai kebutuhan dan sesuai lokasi. Pada Gambar 13 merupakan contoh layout tampilan ketika user terkoneksi melalui jaringan internet dengan layout media promosi PHATH.

\section{Kesimpulan}

Sistem ini bisa lebih ditingkatkan dengan menyediakan berbagai pilihan. Dengan voucher pembelian Internet tambahan atau media promosi lainnya, sedangkan untuk keamanan, terutama untuk 
koneksi yang menggunakan model internet / wan bisa diupgrade menggunakan keamanan yang terenkripsi untuk jalur koneksi.

Aplikasi portal captive berbasis lokasi ini dapat memberikan kemudahan bagi pengguna hotspot baik di dalam LAN maupun di jaringan WAN. Hasil ujicoba dari jaringan WAN dilakukan ujicoba melalui internet indihome di beberapa rumah sivitas STIE Perbanas Surabaya, disamping memberikan pengguna keamanan dan kenyamanan mengakses data lokal yang berada di Perbanas Surabaya pemanfaatan lain adalah penggunaan akses journal ebsco yang hanya dapat diakses oleh tanpa authentifikasi melalui IP public jaringan Perbanas dapat diakses melalui captive portal jaringan WAN sivitas. Kelemahan dari captive portal system berbasis lokasi untuk jaringan land an WAN adalah ketergantungan terhadap router mikrotik.

\section{Ucapan Terimakasih}

Ucapan terima kasih kepada segenap sivitas akademika dan teman ICT STIE Perbanas Surabaya yang telah mendukung mulai dari diskusi perencanaan, tahapan implementasi web portal dan ujicoba sebagai media promosi dan penentuan lokasi user pengguna hotspot di lingkungan kampus maupun di luar kampus.

\section{Daftar Pustaka}

Aryanto, M.F.N, dan Cahyo, S.B.N., 2014. Membangun website portal sebagai sarana penyewaan barang dan jasa di Yogyakarta. Tugas Akhir, STMIK Amikom, Yogyakarta

Candra, I., 2015. Media iklan web berbasis lokasi dengan memanfaatkan segmentasi jaringan pada lokal area network. Seminar Nasional "Inovasi dalam Desain dan Teknologi" - IDeaTech 2015, 18 .
Goeritno, A., Aprianto, Y., Hasri, H., Rizkal, 2017. Penerapan integrasi captive portal dengan Single Sign On (SSO) pada layanan hotspot dan sistem informasi akademik dan keuangan (SIAK) di Fakultas Teknik. Seminar Nasional ke-2: Sains, Rekayasa, \& Teknologi UPH, 27 Mei 2017.

Haryadi, M.A., 2016. Perancangan media otentikasi menggunakan captive portal pada jaringan wireless laboratorium komputer Teknik Elektro Universitas Diponegoro. Transient 5 (2), 1-8.

Hermawan, D.K., 2011. Implementasi Bandwidth Management Captive portal pada Jaringan Wireless di PENS-ITS", D4 Teknik Telekomunikasi, PENS Institut Teknologi Sepuluh Nopember.

Hermawan, D.K., Sudarsono, A., 2010. Implementasi bandwith management captive portal pada jaringan wireless di PENS-ITS. Makalah. Surabaya: ITS.

Madjid, N., 2006. Perbandingan SSL (Secure SocketLayer) dan IPSec (Internet Protocol Security) pada VPN (Virtual Private Network). Skripsi, Teknik Informatika. ITB . Bandung

Rafiudin, R. 2004. Panduan Membangun Jaringan Komputer untuk Pemula. Elex Media Komputindo. Jakarta

Setiawan, H., 2013. Rancang bangun captive portal untuk jaringan wireless hotspot berbasis open source pada cv. gempar production palembang. Journal Mahasiswa Teknik Informatika, 1-8.

Sukmaaji, A., Rianto., 2008. Jaringan Komputer : Konsep Dasar Pengembangan Jaringan dan Keamanan Jaringan. Andi. Yogyakarta

Supriyono, A dan Riadi, I., 2013. Rancang bangun sistem hotspot menggunakan captive portal. Journal Sarjana Teknik Informatika 1 (1), 1-9

Yutanto, H., 2015. Manajemen tata kelola captive portal hotspot mikrotik \& unifi controller. Journal e-NARODROID 1 (2), 74-79. 